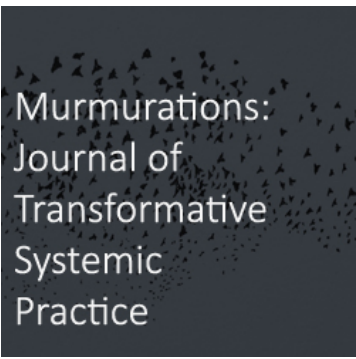

Volume 3

Issue 2

Spring 2021

Keywords:

reflexivity, autoethnography, integration, counsellor training, psychotherapy training, contextual learning, personal professional development

\section{Citation Link}

\section{Meadow. "Patchwork of Practice" as autoethnography for personal and professional development}

\author{
Bev Meakin
}

\begin{abstract}
In this paper, I demonstrate the use of an exercise that I devised as a teaching intervention for student counsellors and therapists - Patchworks of Practice (Meakin, 2019). It facilitates exploration of contextual influences on their human being and aids reflexivity on how these influences shape their practice.
\end{abstract}

I explain how Patchworks of Practice work and show how I adapted the exercise as a form of autoethnography. I share learning of the process and findings from one part of my doctoral research in which 1 used autoethnography to explore how my personal influences shaped me and my way of working as a couple therapist and as a university lecturer teaching on counselling courses. I use examples of my own patches and my reflections on them to illustrate the reflective research process and discuss my learning. The Patchworks of Practice exercise has been useful in collating different theoretical concepts for me as a couple therapist and my approach to teaching. It offers a way of highlighting resources for navigating professional landscapes particularly in times of uncertainty such as during the pandemic.

In this practitioner research, I extend the patchwork metaphor to a rural landscape to communicate how I see my life and the contexts in which it has evolved - and which have shaped it. I hope this paper will inspire others to use the Patchwork of Practice exercise in their own reflexive learning, selfsupervision and research.

\section{Beginning}

In this piece, I write from within personal experience. You will glimpse parts of my family, social and cultural worlds which are probably different from yours and yet you may feel some resonance or see stark contrast. I expect you read with a systemic curiosity and reflexivity, alert to your embodied responses to this writing. Perhaps you will go further and explore those further and create further knowing; rhizomes of reflexivity that stretch out and influence how you go on. As I write this paper and tell my story, I hope to engage you and widen my learning in the process. 
As therapists, we take ourselves into our work; we are the tools of our trade. A therapist's human being is integral with and influential on their human doing and human relating with clients. However, therapists have differing beliefs around the concept of self or selves; some may see no self as separate from a relationship context. In my therapy work, I aim to establish a collaborative therapeutic relationship that is nurturing and accepting, that has potential for growth and change. It is important I am aware of influences on my way of working and being with people in order to be as effective as possible with clients. It is important I am reflexive and relationally responsive, to notice when I am less effective and attend to this. This this practice of being reflexive on the personal and professional interface carries into my teaching role.

\section{Patchworks of Practice exercise}

I teach on Diploma and MSc counselling courses that cover a variety of theoretical approaches alongside facilitating student counsellors to develop an integrative approach. An integrative approach is a blend of different theoretical concepts that is more useful to clients that a single theoretical approach (Cooper and McLeod, 2011). Integration isn't straightforward when philosophies between modalities differ and sometimes compete. I noticed students struggle to find a way of working that felt right for them. They looked for a sense of a single "correct" approach from theoretical orientations they were following; they didn't have a clear "how to" guide to become integrative counsellors.

Akister (2005) adapted a patchwork assessment tool (Scoggins and Winter, 1999) for a systemic module on a social work training. I was struck by parallels between weaving pieces of writing on different areas of the curriculum into a patchwork text and bringing together different theoretical concepts into a counselling approach. Scoggins' and Winter's (1999) aim is "to encourage students to make their learning into a process of constructing meaning... and help students experience the acquisition of knowledge as a process of personal process of self-exploration and self-questioning" ( $p$. 486). The reflexive element of "self-exploration and self-questioning" in "constructing meaning" chimed with the rationale for personal and professional development that is a feature on counselling training.

I developed the Patchwork of Practice exercise (Meakin, 2019) around this rationale; it became a tool to explore personal and professional influences on a developing integrative counselling approach. The patchwork exercise helps student counsellors reflect on their personal values, beliefs and experiences, and see these from other perspectives. They become more aware of how these aspects influence their counsellor role and approach. Self-reflexivity and relational reflexivity are promoted and are key to exploring this personal professional interface (Burnham, 1993; Burnham, 2005).

I introduce the Patchwork of Practice in the first few weeks of counsellor training. This coincides with a lecture on reflexivity. The patchwork exercise is as follows (quotes are from my teaching handout):

- A brief explanation of the rationale behind the exercise, "the aim is to aid the process of integrating theory, ethics, personal development, skills and practice towards your evolving counselling ethos. The Patchwork of Practice is a reflexive process and encourages a holistic view of your developing counsellor role".

- Students are asked to create a patch about any aspect of the course or themselves that has caught their attention; "Patches can include: a critique of a paper, your response to a theoretical concept, thoughts on an ethical dilemma, your reflection on a piece of skills 
practice, some personal insight, reflection on a PD experience, etc"

- A patch can be in any medium, "writing, art, poetry, or any medium that expresses your thoughts and feelings".

- The students are assigned Patchwork Groups of four; there are guidelines, such as - facilitate other's reflexivity, think about links with counsellor role, respect for differences, notice the impact of others' perspectives or Patches on you.

- There are timetabled slots of one hour to create a patch. These are at the end of the day so the patch can be created at home. The following week Patchwork Groups meet and share patches; these sessions are timetabled for an hour.

- The purpose is clarified further; "The patchwork exercise is part of the integrating process throughout the 2 years on the Diploma. It is an evolving exploration and development of you as a counsellor; so, openness and curiosity help, there is ethical thinking, critique and respect rather than rights or wrongs. The patchwork process links with your journal as a reflexive tool throughout the course."

In the early days of using Patchwork of Practice I had enthusiastic responses from students about how useful and creative the process was. This led me to explore the experience of the exercise myself as autoethnography, and with students through action research that will be the topic of a future paper.

\section{A Landscape Patchwork}

In the early months of my research, I noticed a link between patchwork and nature. From early childhood, I have always been drawn to being outside and developed a love of nature, particularly a rural landscape; I see this landscape as nature's patchwork.

In my doctoral thesis, I developed the overlaps of patchwork and landscape further. I gave chapters headings from the theme of the landscape metaphor; autoethnography was "Meadow and Stream: a reflexive journey through a personal and professional landscape" (Meakin, 2020). This paper focusses on Meadow; Stream will be the topic of a future paper.

Meadow explores the ecology of my way of being (Anderson, 2001). I am a mother, grandmother, partner, friend, gardener, counsellor and teacher of counsellors. My identity and how I relate with others in these roles, and niches, is influenced by cultural and environmental contexts, social identities, family and personal history (Burnham, 1993).

Stream is my professional practice; here I am influenced by personal values and beliefs inherent in my way of being, as well as my counsellor training and ongoing supervision. I looked at how my integrative counselling approach evolved. Stream has a quality of flow that evokes continual movement, flexibility and evolution. As a stream flows through a meadow it waters and feeds the plants with nutrients; it moves nutrients and waste onwards. This mixing of the two habitats mimics the continual cycle and flow between personal and professional.

A Meadow helps me pause to take in the diversity of plant life, birds and insects that support each other through seasonal growth and succession. I can pause to rest, or to turn my gaze inwards and wonder about evolving patterns in my life, or look outwards at the wider world, relationships and history that shaped me. There is peace and space. The exploration in Meadow needed these 
conditions, and time, for an autoethnographic process that involved creativity, detailed observation and reflection. Learning illuminated key experiences in my cultural, social, and family contexts.

Bateson (2002) explored the importance of context, relationship and circular interaction between parts of a system in developing understanding and meaning of interactions. He applied principles of binocular vision and seeing "in depth" - "so the understanding (conscious and unconscious) of behaviour through relationship gives a new logical type of learning" (Bateson, 2002, p. 125). I understand this to mean that learning of any kind, makes more sense when there is relationship with the context, rather than learning about something, at a distance from it.

\section{Autoethnography in Meadow: an individual Patchwork Process}

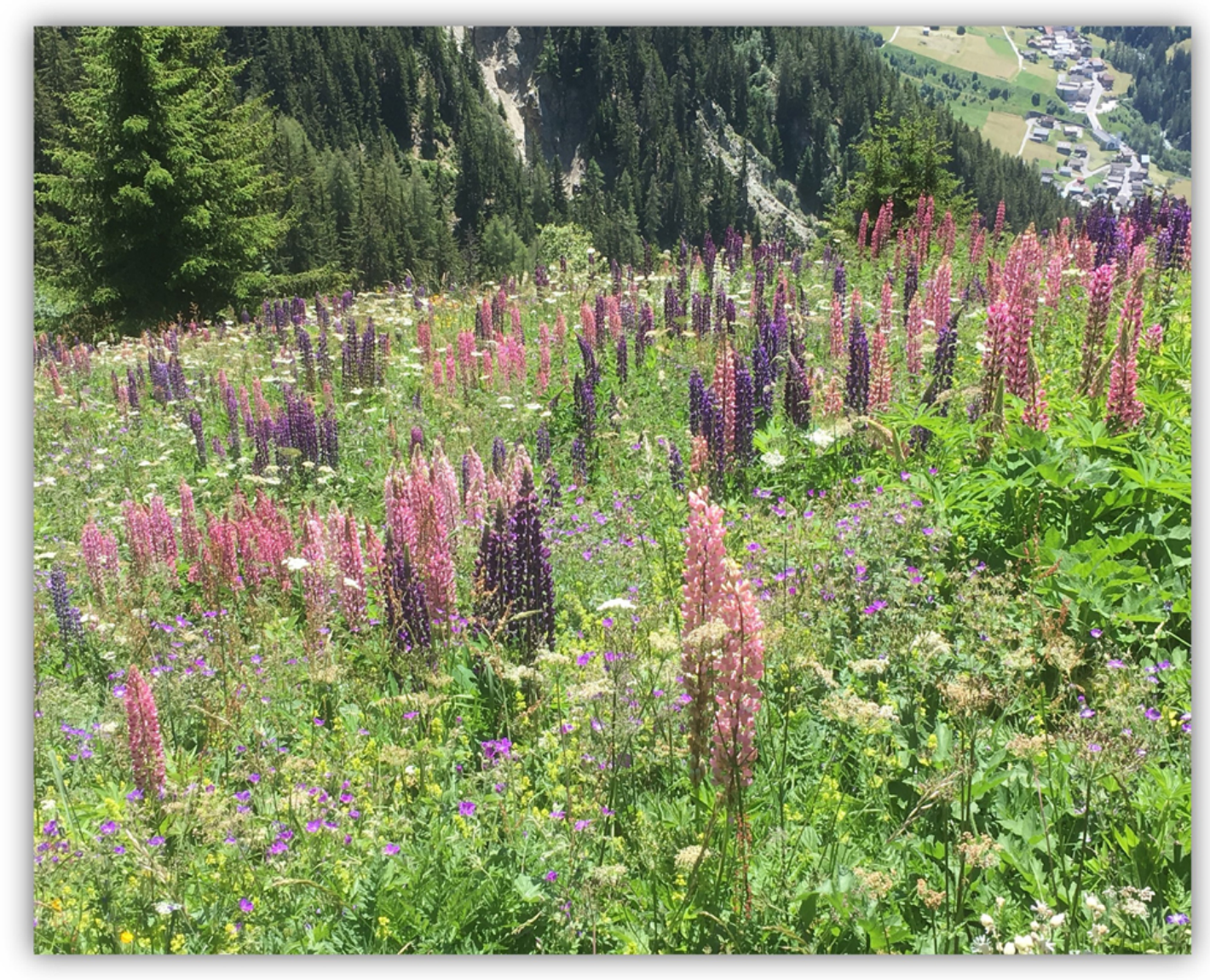

Wildflower mountain meadow

(photographed by B. Meakin)

The autoethnographic method in my Meadow patches followed the pathway student counsellors tread with the Patchwork of Practice exercise. I created patches, however there wasn't opportunity to share these with others as student counsellors would do. So I noted and explored my reflections on each patch and any associated reflexive writing; this is exploration from outside a patch and writing. I also reflected on my experience during the process of creating the patch; reflection from within creating of a patch.

In previous personal development work, I used a journey metaphor. I drew my life as a timeline and 
marked key experiences along it, some evoked the way of life then or were tipping points changing that way of life. I repeated this exercise as a starting point to the autoethnography. If I think in terms of patchwork or landscape, there is possibility of overlapping layers or joining of patches. The journey has a sense of moving on from one area to the next. In life this doesn't always happen, experiences or ways of living life are concurrent. For example, I have been a part of my family community at the same time as learning about different communities and groups when starting school. If there is a sense of moving on, as in divorce maybe, then aspects of history remain as influences in a person's polyphony of voices (Shotter, 2010).

My work pattern as a lecturer allows for more opportunity to take leave over the summer months. I chose to write the Meadow Patches partly on holiday in Switzerland and partly on study leave over that same summer period. It was important to have protected space and it helped to be in a beautiful place; this was either looking over the Alps or in a quiet room at home where I felt peaceful.

To decide which patches to create I looked at the journey first, selected experiences I felt were life changing and/or relevant to my life now. Some patches were poems, some photographs with writing expressing thoughts, feelings and memories the picture evoked. Writing could be reflexive (Bolton, 2014, p. 138); find a peaceful and comfortable space, write without thinking about grammar, spelling and punctuation. I wrote for as long as I wanted to. I read back the patch to myself and noted my responses. I moved away from the writing.

The next step was a deliberate reflexive look at the patch that mirrored taking a patch to a group. This involved rereading a finished patch and noting my responses. I tried to notice emerging values and beliefs, emotions in the experience; I tried to look at myself from a perspective of another. I wrote a reflexive piece for each patch. These informed my picture of who I was, the multiple relationships, voices and experiences that shaped me; writing these patches led me to see how I make sense of the world (Richardson and St. Pierre, 2018). Writing was sometimes joyous, moving and often sad; I was "not flinching from where the writing takes one emotionally, or spiritually, and honoring the embodiedness and spatiality of ones labors" (Richardson and St. Pierre, 2018, p. 824).

The focussing in and focussing out reflexive process in and on the writing can be likened to the stages of a Heuristic research process; engagement, immersion, incubation, illumination, explication and creative synthesis (Moustakas, 1990). I have had a sense of preparation, exploring and refining the topic as engagement; writing of patches as immersion; moving away from writing as incubation. Heuristic philosophy endorses personal resonance of this topic; "a question that matters personally (and) there is a social---perhaps universal---significance" (Moustakas, 1990, p. 15).

I am sharing in this paper a couple of patches with accompanying reflexive writing as examples of different creative ways of expressing experience and my reflexive process. The first is a poem expressing the comfortable rhythm of my life in a rural village as a child. I was aware of seasons and weather and felt connection to nature from an early age. The second is the story of the day my Dad died; a shock that flows into grief and leaves an ongoing legacy. 


\section{Patch 4}

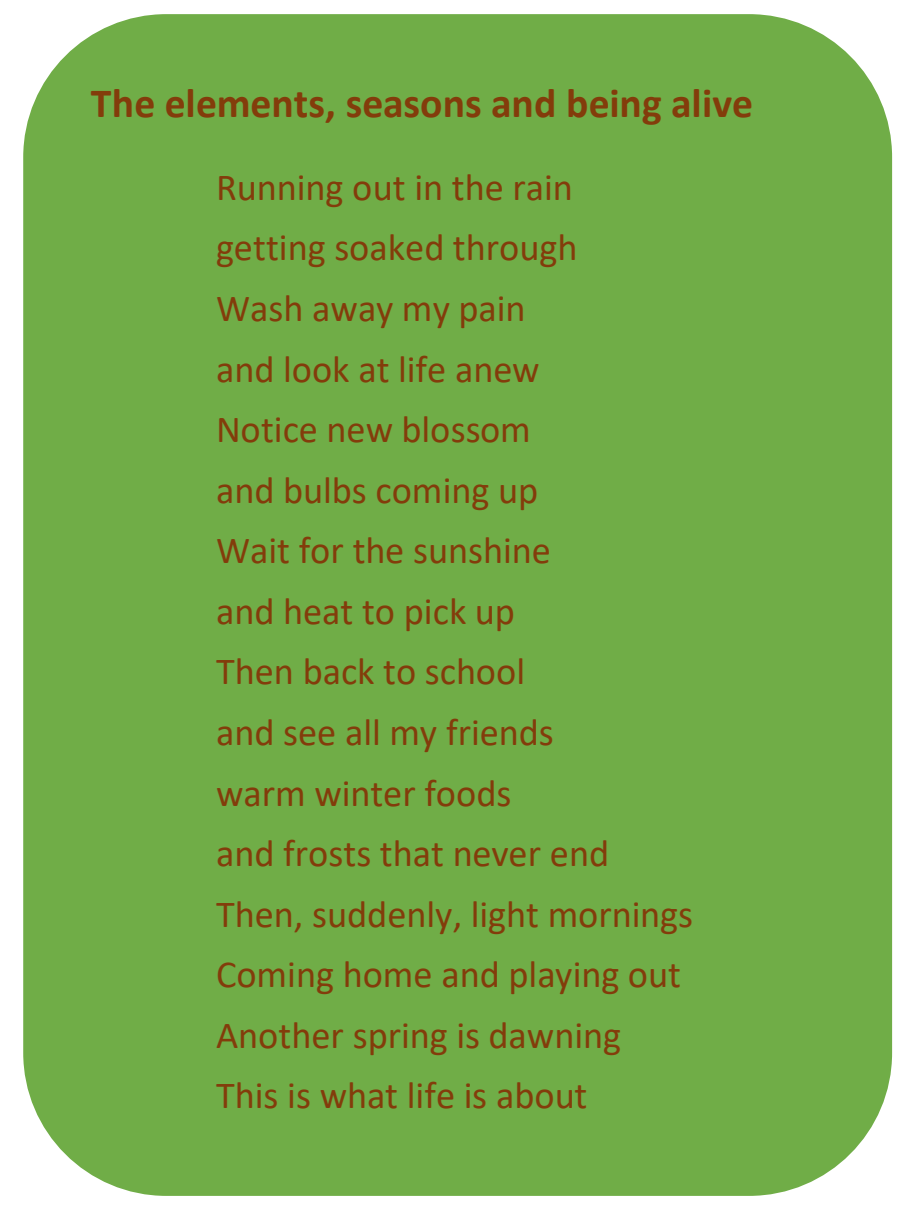

I wrote this poem as a patch after a trip to a new café in Bruson, Switzerland. Next, I lay a few moments in a deck chair, noticing nature all around me and remembering sunny days of school holidays. The poem was a struggle to capture the experience. It did seem to clear away undergrowth, formality and planning though and a second poem flowed more easily.

\section{Reflection and Reflexivity on Patch 4}

This patch announces spirituality. I experience a need to feel at one with the elements when sad or stressed. I would go for a walk in a storm and know there is a greater force than man or society. This would feel healing and energising.

Nature is part of the wider ecology and part of a spiritual sensing. The miracle of growing your own food, the rhythm of the seasons and weather, the beauty in meadows, trees, stream, pond, sea and sky. This is available to connect with and part of life, growing up, experiencing developmental change, loss and renewal.

This has endured throughout my life Emotions: joy, security, wildness and healing

Beliefs: spirituality linked to nature and environment. The importance of connection with nature for well-being. The infinity and awesomeness of the natural world. 


\section{PDSP Journal Extract:}

"My senses are awakened, from time to time the clouds cover the sun and shadows play over the mountains; so beautiful. I feel warm and sleepy, gorgeous food and coffee, hay still being made, and grass scents fill the air. I hear birds, a tractor, a hedge cutter, a helicopter flies by. The paragliders drift over the valley; peace".

The second patch I'm including here is written from within a very familiar memory...

\section{Patch 5}

\section{Death, loss and renewal}

I was twelve years old; my brother was ten and my sister four. On Monday 15th September 1969, my Dad took me to school and continued on to work. I got the bus home as usual and he was expected around $6.00 \mathrm{pm}$. Then Mum received a phone call to say he had been rushed to hospital. Time is distorted. It seemed she went to the hospital; my brother and I took the dog for a walk and when we returned home Mum was back. My brother seemed worried and I tried to be reassuring. He went in the house first and we were told that Daddy had died; shock and numbness. My brother started to cry, and I remember thinking that I better cry, or they might think I didn't love him. The thought was very calm and quite detached; I felt frozen. Once I started to cry, I couldn't stop.

The next day I was sent to school as usual. A family friend gave me a lift and asked after my parents. I calmly told him that my Mum was fine, but my Dad had died. In order to cope I continued to minimise what had happened. Some days it didn't feel like the loss was real even though I knew it to be true. I just tried to carry on as normal. I was fully aware intellectually that my Dad had died but it took a long time to be real emotionally and find ways to cope with anger, sadness and helplessness.

I wasn't allowed to go to the funeral and felt furiously angry with family friends who did and were still at our house when I returned from school. I buried my anger at this time, inside screaming "why are you here, he was MY Dad". Then over the next few years I would go running in the fields behind my house or play hockey, rather than acknowledge it or express the anger. I was very angry with my Dad for leaving me and often with my Mum for all sorts of things.

I began to have difficulty concentrating at school, I felt different from my friends, I didn't fit in. I would love to go to bed very early to read but still felt tired all the time. I was still sad and had little motivation, maybe depressed? To help myself cope with this I became 
close to my Mum, trying to help her all I could, and I played sport.

The school I attended was founded to care for orphaned or necessitous children, and they boarded. My Dad had paid into a Foundation Fund, nine guineas, and our family could benefit from the scheme if anything happened to him as bread winner. So, my brother and sister also left to board at the school. The further loss increased my attachment to my Mum. I became her support. This provided a secure base for me by keeping us close. If she went out, I would make a meal or clean the house to surprise and please her.

I had private memories of my Dad that were special to me and cheered me up. I saw my brother and sister at school and at weekends or holidays. My Grandad was always there at home, or in the garden or allotment. The fields, farms and gardening were part of our lives; active, familiar, nurturing and creative. I was part of a caring family and community.

At fifteen I was starting to enjoy life more, I could go to the parties, play sport; I matured physically but less so emotionally and was wary of any intimate relationships. At seventeen I thought I was fine, although unable to leave home to go to university.

Seven years on from when Daddy died, I felt quite happy, and each Saturday night I met with a group of friends from the next village. I discovered camping trips and walking in the hills with them. I started to go out with a boy, and my Mum started to go out with friends and had some "suitors", at 48 years she had a life ahead. So, life took a new turn for both of us.

\section{Reflection and Reflexivity Patch 5}

As I read through this I am struck by the enormity and suddenness of what happened, my world was turned upside down. I feel fortunate to have had resources to help with the grief, and very fortunate to have had a Mum who believed in surviving. Yet there was unacknowledged sadness for me, and signs of grief went unnoticed by others, and myself.

I have not acknowledged the importance of what stayed the same before writing this.

These aspects were important as support through grief. They informed me how to cope with my own grief in future losses and bereavement.

I note the importance of environment and nature again, and the physical exertion in sport; fostering a healthy mind and body.

Emotions: Loss, sadness, anger, alone, empty, world turned upside down, different, fear of further loss and new intimacy

Beliefs: I can survive, women can cope, the worst can and does happen, life goes on, keep going 


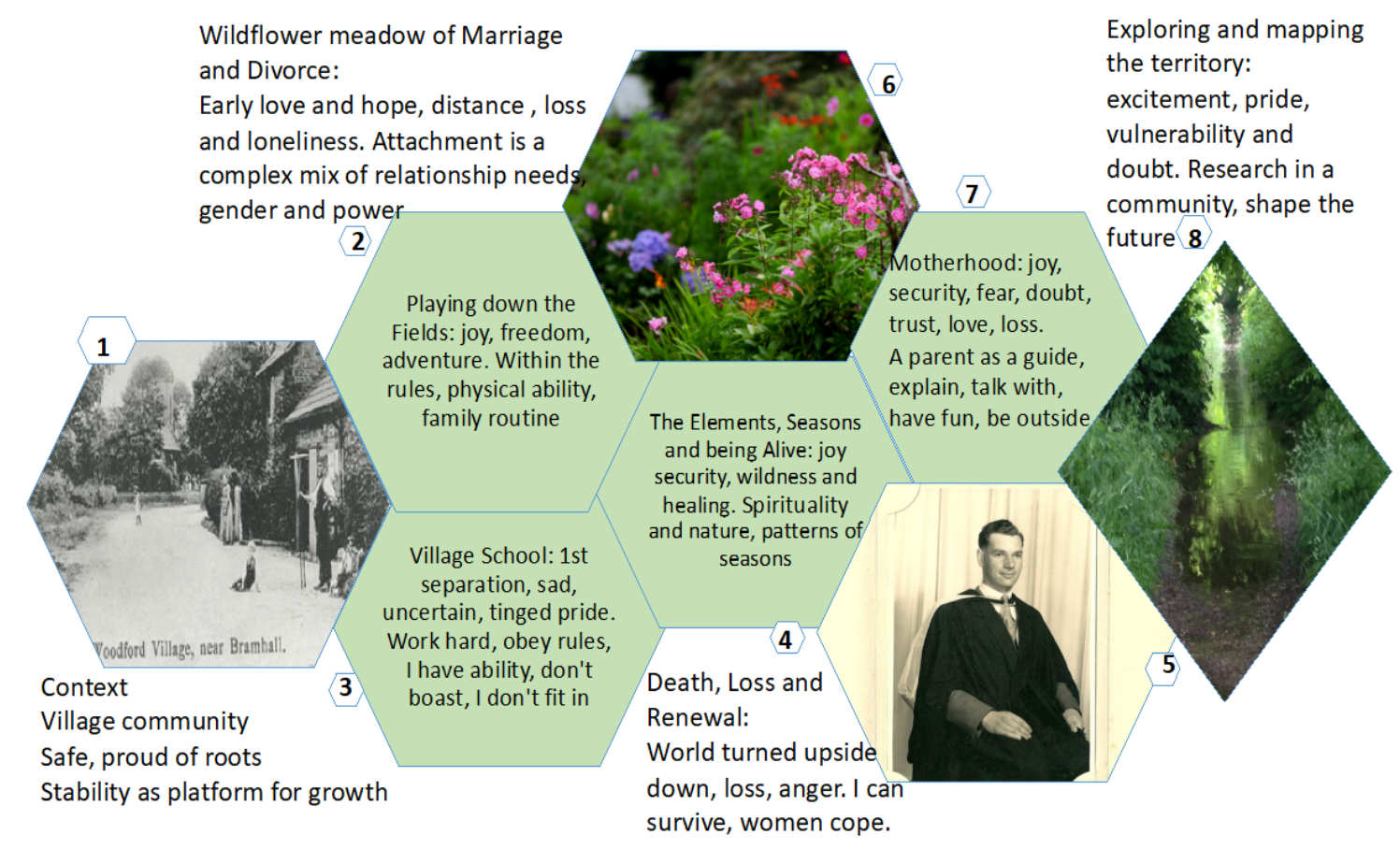

\section{Summary of my Patchwork Process}

This Patchwork diagram follows the hexagonal layout used in stitched patchwork. It shows influences from my early life (1) in a village community (the family photograph is of Woodford Village circa 1904), where strong family traditions and a rural setting provided a nurturing environment with space to grow. Patch (2) develops a sense of freedom, contained by clear boundaries, in playing down the fields. School life (3) was a first separation and sometimes a struggle to fit into friendship groups. Early learning of differences within communities, and of my own abilities. These led to feeling my way in the wider world. I developed a sense of rhythms of nature, seasons and patterns of living (4), a feeling of connection with the natural world that sustains me today, a spirituality. In Patch (5) life changed in a moment. The experience of my Dad's death changed my path, I knew the worst can and does happen (family photograph of my Dad at his graduation). An early marriage (6) was one solution to the huge loss in my life. It was a new start yet with a legacy of loss (the photograph is from my garden). New shoots (7) blossomed and the privilege of motherhood. Where next (8)? Curiosity urged me to explore this path and embark on this research journey (photograph of my path to work).

\section{Integrating Patches and theory: a reflexive weaving}

In this section, I discuss and link themes from the patches, linked experiences, and reflections on the patches. I take a critically reflexive view of the landscape that they form together and explore layers of context and influences, critique ideas. I have used a bold font for words that capture key themes.

My written patches describe some tragic moments, sudden points of change alter the direction of life's path, such as death of my father, my divorce and death of my mother. They also portray day to 
day living, learning and experiencing at certain points in time. They show a tragedy happening in a context. Bereavement and emotions of grief changed the lives of our family and community, upended our usual patterns of relating. In reflecting on the patches I'm struck by the importance of knowing myself in context; knowing my rootstock (ancestry) and myself as a stem grafted on, the propagation and environmental history of the person I have become. A gardener would select rootstock specifically to influence characteristics such as disease resistance, size, blossom and fruit. In propagation "the amazing meristems of the cambium layer of either plant dividing together and merging as one create a new specimen" (Rigler, 2015). Similarly, the metaphor of Landscape, includes this "growing together", me within influences of the landscape; this is a circular relationship.

Community appears in several patches; in the rootstock, in family and in my evolving journey as a teacher and researcher. "An ecological community is a group of actually or potentially interacting species living in the same location" (Nature Knowledge Project, 2014). The ecology of a community includes non-living components of the environment in which the community lives, the network of influences.

The village community supports the family community into which I was born and grew up. As I wrote Patch one, I had a strong sense of belonging, then and now I notice the sense of security I link to this. This is not only about people, relations and friends, it is about the culture of growing, seasons and a rural environment that was and is so familiar. It operates as a secure base system in terms of Attachment Theory (Bowlby, 1969). In times of stress or perceived stress attachment behaviour is activated; I could reach out to family or nature and there would be a response attuned to my needs and consistent enough to settle the affect (Holmes, 2001). In a secure base system, an attachment figure is usually a parent, or main carer, for me the sense of place and a family response are also important. I see a secure base as including these wider aspects. Byng-Hall (2008) describes family attunement and responsiveness in developing interactional awareness and a sense of family security. Dallos and Vetere (2006) also acknowledge cultural elements in development of attachment patterns.

The beginnings of a therapeutic relationship or starting a course with a new cohort can be seen through an attachment lens (Connors, 2011). This is a key aspect of my way of being in my work, paying attention to anxieties as something new starts and working to provide a settling, containing environment for all.

There are complex relationships within a community. They can be symbiotic or competitive, predatory or nurturing; exerting different influences on community members (Nature Knowledge Project, 2014). Community continued around and after the death of my Dad, supporting my Mum, yet I felt on the outside. Similarly, in the school community, I had awareness of difference and feeling on the edge of groups or rejected by them. In certain research communities, with more Cartesian style philosophy of hypothesis and proof (Shotter, 2010), this pattern repeated, leaving me distanced and unfulfilled.

Shotter (2010) believes we are inextricably bound to a way of living and thinking that follows Descartes' picture of the world, we are seen as particles and matter in space and time; "the picture holds us captive" (p. 15). The picture is always observed from the outside. Research tries to understand and master the picture. A social constructionist perspective imagines us within the picture, active participants with and in a dynamic ecology. In autoethnography, I am participant and mutual interactions with others in my life shaped stories over time.

It is interesting to see resonance of the community theme in Patch 1 with Patch 8, written during the 
research. I reflect on the importance of a research community for me, and notice I have agency to create this with others. Without this patchwork process I do not believe I would have this level of understanding of myself as a researcher, nor belief in my ability to contribute within a research community.

This theme and the subtle differences woven through inform my way of being in teaching and therapeutic communities. I am more aware of my influence and how I may be influenced by others. I can be vigilant for emotion and experience noticed in the patches; anger, distance, feeling "at home" or "on the outside".

I notice different levels of community in the patchwork, more specifically, relationships within a community. I focus in from historical village community, to school friendships, then through family and parental relationships to intimate couple and right down to my individual relationship with the environment. A landscape has strata of rock, earth and living species evolving over time. Historic boundaries and settlements can be seen as mounds, roadside banks or ditches in today's countryside (Hoskins, 2013); earlier contexts that physically shape the current landscape. Similarly, I see this layered effect in the strata of relationships, with one layer influencing the others (Oliver, 2007). However not necessarily in a hierarchical way as portrayed in theories of co-ordinated management of meaning (Pearce, 2007).

Strata of relationships have a chronological dimension and can overlap as family and intimate couple relationships do. In addition, within each layer, there is "local" context. This may be who is involved, events, environment, what is communicated. As explained earlier there is a "network of influence" in an ecological community (Nature Knowledge Project, 2014). If I apply this to my Landscape, the meaning of any interaction or episode described in patches cannot be understood without understanding the relational stratum and the context.

In this thinking I'm also influenced by a narrative approach; ideas of my life as a story, with a plot and characters, evolving over time in landscapes of action and landscapes of meaning (White, 2005; Morgan, 2000). Bateson (1972/2002) also noted the importance of context in understanding meaning.

To give a specific example - I am proud of my farming and horticultural background, have a sense of roots in a rural community (cultural voice and relationships). Patches show the early years, playing down the fields, growing our own food and mealtimes revolving around daily rhythms (family of origin). I have a relationship with nature, a sense of spirituality, noticing seasons and the beauty of natural landscapes (spirituality). These layers distil to aspects of my current lifestyle such as "being in the garden" and keeping hens. When stressed or sad I feel healing and peace developing through time spent outside, gardening; an inherent cultural quality of nurture and growth is part of my way of being (Anderson, 2001), and a quality transferable to counselling and teaching.

I have described this example to a fellow research student, who had a mental image of me walking through my garden, tending plants, noticing new flowers. "I see this gardener as a beautiful analogy of you as teacher with the polyphony of voices from within your personal and cultural narratives coming through in a way of being with students" (Urbistondo Cano, 2016).

Earlier in this discussion I noted the influence of a secure attachment in the ways I begin with groups and with clients in therapy. It is useful to return to this aspect and discuss how it links with change. Change is interesting as a universal phenomenon whether studied environmentally in how ecological 
communities respond to "disturbance" (drought, fire, weather extremes) (Nature Knowledge Project, 2014) or students as they develop through a programme of study or clients wanting change through a therapeutic process. As a teacher and therapist, I think it important to understand my process of change and how this influences my belief in helping others negotiate theirs.

In looking at change and ongoing development, Patches show sudden enforced changes through loss, developmental change over time and transformative change for example through motherhood and in my master's research. Connors (2011) notes the benefits of Attachment Theory as an integrative framework for psychotherapy due to its strong evidence base and focus on developmental process. Bowlby (1969) used the phrase "from the cradle to the grave" (p. 152) to show the lifelong importance of a secure base in order to continue to explore the world and change. Connors (2011) summarises the role of a person's attachment history in creating a map, internal working model (IWM), which informs future relationships and process of change. She looks a spectrum of attachment behaviours, from autonomous to more dependent.

These ideas resonate with some aspects of experience; in Patch 2, an experience of a secure base promoted autonomy, confidence and freedom to explore; in Patch 3, separation for the first time was noted, anxiety, and importance of reunion at tea time were key; Patch 5, death of an attachment figure lead to a re-working of an IWM, a dip in confidence and more anxious style of relating followed, in order to protect myself from further loss. There are signs of grieving as summarised by Connors (2011). I note beliefs of "women can cope" and "keep going" bring support throughout change. In each Patch, experience relates to aspects of Attachment Theory, and these offer partial explanation for conditions for change, as well as impact of loss and separation.

Dallos and Vetere (2006) include systemic and narrative approaches to compensate emphasis on dyadic relationships in Attachment Theory. The importance of context, power, diversity and possibility of re-authoring stories of relationship are available in their integrative approach. Similar to Connors (2011) they apply ideas of attachment in creating a secure base in therapy and working with communication and change.

From the experience of writing these patches I note the importance of embodied sensing and expression, for example in Patch 2, playing down the fields, and Patch 4, elements, seasons and being alive. To some extent this is noted by Dallos and Vetere (2006) as physiological and emotional affect in attachment relationships. However, Shotter directly addresses the importance of developing

inquiries into how to become more well oriented within our surroundings, to develop a set of embodied-readinesses-to-respond, spontaneously, to a whole range of socially significant occurrences, in ways that the others around us will recognise as both intelligible and legitimate, and which are ecologically satisfactory to us

(Shotter, 2010, pp. 223-224)

This sentence captures the possibility of working in therapy, in education, being in relationships and alone, in such a way that there is a "bodily" knowing how to go on, "spontaneously", learnt from birth and within a community. In addition, this informs a dialogical process and communication alongside language. Shotter (2010) stresses that "withness talk" when intermingled with action, in the moment, can bring about a different order of change from reflection on an episode after the event (p. 224). Patchwork of Practice provides opportunity to combine both; withness...in the moment (creating a 
patch and initial reflection) and aboutness...reflection on the patch (with a group).

\section{Experience of this Patchwork writing}

Patchwork process in the Meadow Patch was a deconstruction of present-day me to uncover some aspects of my landscape in order to understand the ecology and develop coherence between this and my way of being professionally (Anderson, 2001). Shotter refers to this as an "ontological social constructionism" (2010, p. 224).

The nature of patches varies, all evoked immediate emotion in the creation and in reading back. They provided a step back into the past to relive and evaluate that time and space in the landscape. I was taken aback by spontaneity of emotion and a sense of re-living moments. Shotter believes

...living moments can make the kind of difference in our lives that matters to us. Their effect can be perceptual, they can move us ontologically; more than just a change in perspective, they can lead us to notice unique things in our surroundings that previously have been missed.

(Shotter, 2010, p. 224).

In the writing, I was aware of noticing and experiencing new aspects of my Landscape. The act of naming beliefs, in reflections, alerts me to attitudes I take into my relationships, my practice and my role as a researcher (Simon, 2014). The qualities of competitiveness, confidence, coping and survival now seem more available to call on as resources personally and professionally. Similarly, I became aware of vulnerabilities and alert to the need for self-care (BACP, 2018).

As I write this paper, in the midst of a pandemic, I notice the relevance of time and place when writing. My doctoral studies were drawing to an end as the pandemic was beginning. I benefitted from this autoethnographic research as I faced new challenges, ongoing uncertainty and losses. I asked for help with technology and I thought I was coping well.

One day I listened to Andrea Bocelli (2020) sing Panis Angelicus and Amazing Grace live from the Duomo di Milano. A film of the occasion showed the splendid building was empty, footsteps echoed in that cavernous space, outside the streets were deserted. I realised I had been getting through by placing myself in a bubble; I had functioned day to day, yet my emotions were outside this protective skin. Music burst my bubble; I turned to patchwork and wrote this piece.

\section{Pandemic Patch: a bubble bursts}

Online and I'm not fine

Quick lessons in Teams

Set up groups

Send invites

All new and explained so well

Who can tell what will happen?

How will it feel?

It's so unreal 
And I will cope.

I wake early and tired

I am in a bubble, safe and scared

Browse Twitter and see

Andrea Bocelli

I listen; I watch the film of the empty streets and beautiful buildings, as the music washes over me

My bubble bursts and tears flow

Sad

beyond words

I remember my Dad

And Grandad

I miss my children

And I want my Mum back.

Thousands of others are crying for loved ones lost

How did we get here?

How to bear this huge loss?

This was a pivotal moment for me. It enabled me to see how I had responded to early messages from another time of loss - keep going, women cope. I was able to move on with resilience and deliberately called on my relationship with nature for calm and space.

I have used my learning to navigate the many changes and uncertainty of the pandemic. Patchwork alerted me to the reappearance of an old way of managing loss and change; detachment from emotion, keep going, carry on, women cope. In these difficult times, it has been a tool for self-care and reconnection. Fishbane challenges western ideals of autonomy and an individuation process with the concept of "relational autonomy that includes both clarity about one's own needs and desires and a readiness for the relational...[this] also entails a relational accountability to the other, and an openness to be affected by the other's response" (2001, p. 276).

\section{Patchwork of Practice as Reflexive Journey}

This reflexive journey through the landscape has informed my integrative approach to therapy and teaching. Autoethnography has been a useful practitioner research methodology. It required that I allowed myself to feel vulnerable as I explored and wrote of experiences and re-connected with emotions from within those experiences. I have re-presented my experiences as accurately as possible and used reflexivity as a practitioner researcher to develop an account that shows the social and political contexts (Etherington, 2004). Social and cultural themes appeared within the web of influences. Social Constructionism became an ideological umbrella covering embodied, contextual, relational and individual influences shaping my values and beliefs. I can see how "values and assumptions may be said to pre-exist and influence the choice of theoretical model" (Burnham, 1992, p. 3). 
I connect to theoretical ideas that resonate with the emotion, values and experiencing emerging through the patches. Some are intrapersonal aspects of felt security or loss, others more interpersonal, concerned with community and relationships. At first glance my life has been calm, stable and very "small village"; a closer look showed nuances of different communities, predatory, competitive, and experiences within or on the edge of these. I came to know more about the intermingling of the various niches within my landscape; it is a familiar territory, and complexity has emerged. I now feel better oriented for moment by moment choices in action, and the spontaneous, embodied "readiness-to-respond" (Shotter, 2010, p. 223). In knowing more about me, and the polyphony of voices influencing communications, I feel more prepared for dialogue with another, without conferring a sense of them as "othered" (Shotter, 2010, pp. 86-7).

\section{Using Patchworks of Practice with students}

Students who have used the Patchwork of Practice exercise mentioned the benefits of exploring the personal before the professional (Meakin, 2020). One of the individual participants in my research noted, "at the beginning of patchwork, I was working more on emotions and finding out who I was, towards the end it was more about theory and integration. They have joined together really, the more I know myself then the more I am available and present with clients" (p. 204). Another student reported, "Patches were more helpful as personal development, in exploring identity struggles, emotions, loss and patterns in my relationships on the course" (p. 203).

The space to explore culture and identity is an important part of developing awareness of one's own cultural influences as well as biases and judgements. This has always been vitally important, however, now that the "Black Lives Matter" movement has heightened awareness of the need to go further and decolonise the curriculum and institutional culture, it is possible for Patchworks of Practice to explicitly encourage the presence of other patches such as cultural identity and history, group membership, everyday prejudice.

I have learned to see that the Patchwork Process is a useful relationally reflexive tool for students, colleagues and researchers. It facilitates insight into the influences of one's unique ecology on relating with others through an embodied, experiential journey rather than simply taking an intellectual "aboutness" position (Shotter, 2010). Theoretical knowledge becomes something that is acquired alongside the growth of personal knowing.

I hope you feel inspired to have a go and create a patch or eight!

\section{References}

Akister, Jane (2005). Patchwork text in family therapy, Journal of Family Therapy, 27, 276-279.

https://doi.org/10.1111/j.1467-6427.2005.00317.x

Anderson, Harlene (2001). Postmodern collaborative and person-centred therapies: 'What would Carl Rogers say?' Journal of Family Therapy, 23(4), 339-360. https://doi.org/10.1111/1467-6427.00189

BACP (2018) Ethical framework for the counselling professions. Lutterworth: BACP.

Bateson, Gregory (2002 [1972]). Mind and nature: a necessary unity. Cresskill, NJ: Hampton Press.

Bocelli, Andrea (2020). Music for Hope - live from Duomo di Milano. https://youtu.be/huTUOek4LgU 
Bolton, Gillie (2014). Reflective practice: writing and personal development. $4^{\text {th }}$ edn. London: Sage.

Bowlby, John (1969). Attachment and loss; Volume 1. Attachment. London: Pimlico.

Burnham, John (1993). Systemic Supervision; the evolution of reflexivity in the context of the supervisory relationship, Human Systems: The Journal of Systemic Consultation and Management, 4(3-4), 349-381. http://www.humansystemsjournal.eu/library/volume-4-1993/volume-4-issues-3-4

Burnham, John (2005). Relational Reflexivity; a tool for socially constructing therapeutic relationships, in Flaskas, Carmael, Mason, Barry and Perlesz, Aamaryll (Eds.) The space between: experience, context, and process in the therapeutic relationship. London: Karnac, 1-18.

Byng-Hall, John (2008). The crucial roles of attachment in family therapy, Journal of Family Therapy, 30(2), 129146. https://doi.org/10.1111/j.1467-6427.2008.00422.x

Connors, Mary, E. (2011). Attachment theory: a "secure base" for psychotherapy integration, Journal of Psychotherapy Integration, 21(3), 348-362. https://doi.org/10.1037/a0025460

Cooper, Mick and McLeod, John (2011). Pluralistic counselling and psychotherapy. London: Sage.

Dallos, Rudi and Vetere, Arlene (2006). Attachment Narrative Therapy: integrating systemic, attachment and narrative approaches. Maidenhead: Open University Press.

Etherington, Kim (2004). Becoming a reflexive researcher; using ourselves in research. London: Jessica Kingsley Publishers.

Fishbane, Mona, D. (2001). Relational narratives of self, Family Process, 40(3), 273-291.

https://doi.org/10.1111/j.1545-5300.2001.4030100273.x

Holmes, Jeremy (2001). The search for the secure base. Hove: Brunner-Routledge.

Hoskins, William G. (2013). The making of the English landscape. Dorset: Little Toller Books.

Meakin, Beverley (2001- 2002). Personal Journal, Relate Postgraduate Diploma in Couple Therapy.

Manchester: unpublished.

Meakin, Beverley (2019). A Patchwork of Practice. Therapy Today, 30(7), 38-41.

Meakin, Beverley (2020). Patchworks of Practice; helping student counsellors develop coherence in personal and professional integration. Doctoral Thesis. https://uobrep.openrepository.com/handle/10547/624521

Morgan, Alice (2000). What is Narrative Therapy? Adelaide: Dulwich Centre Publications.

Moustakas, Clark (1990). Heuristic research; design, methodology and applications. London: Sage.

Nature Knowledge Project (2014) Available at: http://www.nature.com/scitable/knowledge/ecology-102

Oliver, Christine (1996). Systemic eloquence, Human Systems: The Journal of Systemic Consultation and Management, 7(4), 247-264. Link to paper.

Pearce, W. Barnett (2007). Making social worlds. Oxford: Blackwell.

Richardson, Laurel and St. Pierre, Elizabeth A. (2018). Writing: a method of inquiry, in Denzin, N.K. and Lincoln, Y. S. (eds.) The Sage handbook of qualitative research. $5^{\text {th }}$ edn. California and London: Sage, 818-838.

Rigler, Russell (2015). Hard graft produces a little magic, RHS Garden Wisley Blog.

https://www.rhs.org.uk/gardens/wisley/wisley-blogs/wisley/january-2015/grafting

Scoggins, Jane and Winter, Richard (1999). The Patchwork Text: a coursework format for education as critical understanding, Journal of Higher Education, 4(4), 485-499. https://doi.org/10.1080/1356251990040405

Shotter, John (2010). Social construction on the edge: 'withness'-thinking and embodiment. Chagrin Falls, Ohio: Taos Institute Publications.

Simon, Gail (2014). Systemic inquiry as a form of qualitative inquiry, in Simon, Gail and Chard, Alex (eds.) Systemic inquiry; innovations in reflexive practice research. Farnhill: Everything is Connected Press, 3-29. 
Urbistondo Cano, Francisco (2016) Personal communication.

White, Michael (1997). Narratives of therapists' lives. Adelaide: Dulwich Centre Publications

White, Michael (2005). Michael White workshop notes, Adelaide: Dulwich Centre Publications.

http://dulwichcentre.com.au/michael-white-workshop-notes.pdf

\section{Author}

Beverley Meakin, DProf, works as a senior lecturer at Staffordshire University and has a private practice as a therapist and supervisor. She is interested in reflexivity around personal and professional development, especially using creative ways to explore this. She especially loves being outside, walking or gardening.

Email: bev@patchworksofpractice.com

URL: https://www.patchworksofpractice.com

\section{Citation}

Meakin, Beverley (2021). Meadow. "Patchwork of Practice" as autoethnography for personal and professional development. Murmurations: Journal of Transformative Systemic Practice, 3(2), 51-67.

https://doi.org/10.28963/3.2.4 